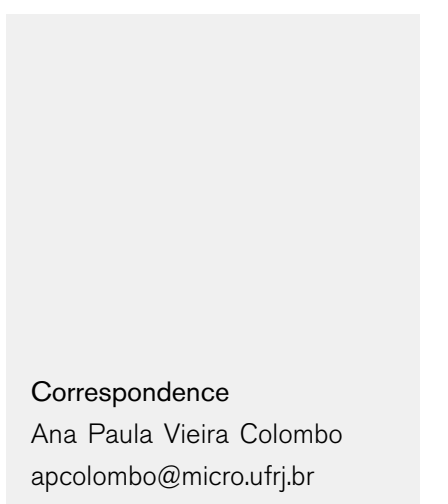

Received 17 November 2005 Accepted 17 January 2006

\section{Identification of oral bacteria associated with crevicular epithelial cells from chronic periodontitis lesions}

\author{
Andréa Vieira Colombo, ${ }^{1}$ Carina M. Silva, ${ }^{1,2}$ Anne Haffajee ${ }^{3}$ \\ and Ana Paula Vieira Colombo ${ }^{1}$ \\ 1,2Institute of Microbiology, Department of Medical Microbiology ${ }^{1}$ and School of Dentistry, \\ Department of Periodontology², Federal University of Rio de Janeiro, Brazil
}

${ }^{3}$ The Forsyth Institute, Boston, USA

\begin{abstract}
Bacterial invasion of host epithelial cells plays an important role in the pathogenesis of periodontal diseases; however, the interactions between subgingival species and the gingival crevice cells are not fully understood. This study determined the prevalence of a group of oral bacterial species on or in epithelial cells derived from periodontal pockets and the gingival crevice of subjects with periodontitis. Samples of epithelial cells were obtained from 120 sites with periodontal pockets $\geqslant 4 \mathrm{~mm}$ and 92 periodontally healthy sites from 49 patients (mean age $46 \cdot 3 \pm 1 \cdot 4$ years; $43 \%$ males) with chronic periodontitis. Bacteria in or on epithelial cells were separated from unattached bacteria by Percoll density-gradient centrifugation. The presence and levels of 33 oral species were determined in epithelial cell samples by whole genomic DNA probes and the checkerboard method. The most frequently detected species were Porphyromonas gingivalis (42\%), Treponema denticola (38\%), Prevotella intermedia (37\%), Streptococcus intermedius (36\%), Campylobacter rectus (35\%), Streptococcus sanguinis (35\%) and Streptococcus oralis (34\%). Species of Actinomyces were found in low prevalence and levels. The data indicated that there were more micro-organisms on or in epithelial cells obtained from periodontal pockets than from healthy sulci; however, no significant differences regarding the percentage and level of any specific species were found between these sites. Veillonella parvula, S. oralis, Streptococcus gordonii and Streptococcus mitis tended to be more prevalent in sites without disease. These findings demonstrated that a wide range of oral species may be detected on or in crevicular epithelial cells from sites with periodontitis and from periodontally healthy sulci.
\end{abstract}

\section{INTRODUCTION}

Periodontal diseases are characterized by chronic inflammatory lesions and destruction of the supporting periodontal tissues, which are associated with specific microbial complexes in subgingival biofilms (Socransky et al., 1998). These micro-organisms may attach to the tooth, to the epithelial surfaces of the gingival crevice or periodontal pocket, and to other bacteria which are attached to these surfaces (Mager et al., 2003). The persistent proximity of the subgingival biofilm to the sulcular epithelial cells plays an important role in the pathogenesis of periodontitis. The periodontal attachment may be affected directly by these bacteria or indirectly through their ability to activate inflammatory and immune processes (Lamont \& Yilmaz, 2002). Yet, the complex relationship between the subgingival microbiota

Abbreviations: $\mathrm{BOP}$, bleeding on probing; $\mathrm{CAL}$, clinical attachment level; PPD, probing pocket depth; SB, supragingival biofilm; SUP, suppuration. and the epithelium of the gingival crevice in such infections has only been partially determined. A great deal of evidence has accumulated which corroborates the ability of putative periodontal pathogens, such as Prevotella intermedia (Dorn et al., 1998), Actinobacillus actinomycetemcomitans (FivesTaylor et al., 1995; Meyer et al., 1996; Rudney et al., 2001), Porphyromonas gingivalis (Sandros et al., 1994; Lamont et al., 1995; Madianos et al., 1996), Fusobacterium nucleatum (Han et al., 2000), and several species of oral spirochaetes (Peters et al., 1999), to adhere to and invade oral epithelial tissues and cells. However, most of these studies were performed in vitro, using few reference bacterial strains, and oral epithelial cell lines, primary epithelial cell cultures or cells from the buccal mucosa. A Percoll density-gradient centrifugation technique has been developed in which the bacteria associated with epithelial cells, isolated from the human gingival crevice or periodontal pocket, can be separated from unattached bacteria and other cells (Childs \& Gibbons, 1988; Dzink et al., 1989; Dibart et al., 1998). Recently, Rudney et al. (2005) have demonstrated that large bacterial masses inside 
oral mucosal cells present a polymicrobial nature, similar to that of dental biofilms. Thus, the purpose of the present investigation was to identify a group of various oral bacterial species present on or in gingival crevice epithelial cells isolated directly from diseased and healthy sites of subjects with chronic periodontitis, using whole genomic DNA probes and the checkerboard method.

\section{METHODS}

Subject population. The subject population was selected from a pool of patients with chronic periodontitis who sought dental treatment at the Department of Periodontology of the Federal University of Rio de Janeiro, Brazil. All subjects were $\geqslant 35$ years of age, had at least 20 teeth and showed at least seven sites with probing pocket depth (PPD) $\geqslant 4 \mathrm{~mm}$ and clinical attachment level (CAL) $>3 \mathrm{~mm}$ at baseline. Exclusion criteria included pregnancy, systemic conditions that could affect the progression or treatment of periodontal diseases, and the use of antibiotics 6 months prior to entry into the study. In addition, subjects requiring antibiotics for clinical monitoring and treatment were excluded. In order to participate in the study, all patients were informed about the nature of the study, and a signed consent form was obtained from each individual. The study protocol was approved by the Review Committee for Human Subjects of the Clementino Fraga Filho University Hospital.

Clinical measurements and sample collection. Periodontal clinical measurements were performed at six sites per tooth at all teeth, excluding third molars. They included PPD and CAL ( $\mathrm{mm})$ measured with a conventional North Carolina periodontal probe (Hu-Friedy), presence or absence of supragingival biofilm (SB), bleeding on probing (BOP), and suppuration (SUP). A trained examiner performed all clinical measurements. Following the clinical assessment, sites to be sampled were isolated with cotton rolls and supragingival plaque was removed with sterile gauze. Samples of epithelial cells were obtained from at least three sites with the deepest periodontal pocket $(\geqslant 4 \mathrm{~mm})$ and bleeding, and three periodontally healthy sites (no PPD $>3 \mathrm{~mm}$ and/or BOP) of each patient using a gentle stroke with a sterile curette. Gingival epithelial cells were placed in sterile Dulbecco's modified Eagle's medium (DMEM; Sigma) supplemented with $10 \%$ bovine calf serum (Laborclin), L-glutamine (Gibco) and L-cysteine (Sigma), and processed immediately.

Separation of epithelial cells from unattached bacteria. Epithelial cells and bacterial clumps were dispersed by aspiration, three times, through a sterile 18-gauge needle. The suspension was washed three times in sterile PBS buffer by centrifugation at $500 \mathrm{~g}$ for $6 \mathrm{~min}$. Epithelial cells with associated bacteria were separated from unattached bacteria using the Percoll density-gradient centrifugation method (Dibart et al., 1998). Briefly, the pellet was resuspended in $50 \mu \mathrm{l}$ DMEM and added to $1 \mathrm{ml}$ of a solution containing $50 \%$ Percoll (Amersham Biosciences) and $50 \%$ PBS. After centrifugation at $11000 \mathrm{~g}$ for $15 \mathrm{~min}$ at room temperature, $500 \mu \mathrm{l}$ of the supernatant containing the epithelial cells was aspirated, washed twice in PBS, and filtered through a $12 \mu \mathrm{m}$ pore-size hydrophilic Nucleopore polycarbonate filter (Whatman). To remove additional unattached micro-organisms and cell debris, $5 \mathrm{ml}$ sterile PBS was passed through the filter. The filters were then put into a sterile plastic bottle and vortexed, and the epithelial cells were collected after centrifugation at $200 \mathrm{~g}$. Cells were then resuspended in $100 \mu \mathrm{l} \mathrm{Tris/}$ EDTA buffer (10 mM Tris/HCl, $1 \mathrm{mM}$ EDTA, pH 7.5), and processed for identification of bacterial species by DNA probes and the checkerboard technique. Samples removed from periodontal pockets contained epithelial cells, red blood cells and white blood cells, as well as individual and/or clumps of bacteria with different morphotypes. After extensive clean-up procedures, including Percoll gradient centrifugation and filtration through a membrane, only epithelial cells with or without attached bacteria were observed by optical microscopy (data not shown). The final sample concentration was adjusted to approximately $1 \cdot 0 \times 10^{3}$ cells $\mathrm{ml}^{-1}$ by a Neubauer chamber.

Identification of bacterial species on or in epithelial cells. The presence and levels of 33 subgingival species (30 species and seven subspecies) (Table 1) were determined using a modification

Table 1. Oral species used for the construction of whole genomic DNA probes tested against epithelial cell samples from 49 chronic periodontitis subjects

\begin{tabular}{|c|c|}
\hline Bacterial species & Strains ${ }^{\star}$ \\
\hline Actinobacillus actinomycetemcomitans a & 43718 \\
\hline Actinobacillus actinomycetemcomitans b & 29523 \\
\hline Actinomyces naeslundii genospecies I & 12104 \\
\hline $\begin{array}{l}\text { Actinomyces naeslundii genospecies II } \\
\text { (Actinomyces viscosus) }\end{array}$ & 43146 \\
\hline Actinomyces odontolyticus & 17929 \\
\hline Actinomyces israelii & 12102 \\
\hline Actinomyces gerencseriae & 23860 \\
\hline Campylobacter rectus & 33238 \\
\hline Capnocytophaga ochracea & 33596 \\
\hline Capnocytophaga sputigena & 33612 \\
\hline Capnocytophaga gingivalis & 33624 \\
\hline Campylobacter showae & 51146 \\
\hline Eubacterium nodatum & 33099 \\
\hline Eikenella corrodens & 23834 \\
\hline Fusobacterium periodonticum & 33693 \\
\hline $\begin{array}{l}\text { Fusobacterium nucleatum subsp. } \\
\text { vincentii }\end{array}$ & 49256 \\
\hline $\begin{array}{l}\text { Fusobacterium nucleatum subsp. } \\
\text { polymorphum }\end{array}$ & 10953 \\
\hline $\begin{array}{l}\text { Fusobacterium nucleatum subsp. } \\
\text { nucleatum }\end{array}$ & 25586 \\
\hline Gemella morbillorum & 27824 \\
\hline Leptotrichia buccalis & 14201 \\
\hline Neisseria mucosa & 19696 \\
\hline Prevotella intermedia & 25611 \\
\hline Prevotella nigrescens & 33563 \\
\hline Porphyromonas gingivalis & 33277 \\
\hline Peptostreptococcus micros & 33270 \\
\hline Propionibacterium acnes & 11827 \\
\hline Streptococcus anginosus & 33397 \\
\hline Streptococcus constellatus & 27823 \\
\hline Streptococcus gordonii & 10558 \\
\hline Streptococcus intermedius & 27335 \\
\hline Streptococcus mitis & 49456 \\
\hline Streptococcus oralis & 35037 \\
\hline Streptococcus sanguinis & 10556 \\
\hline Selenomonas noxia & 43541 \\
\hline Tannerella forsythia & 43037 \\
\hline Treponema denticola & $\mathrm{B} 1 \dagger$ \\
\hline Veillonella parvula & 10790 \\
\hline
\end{tabular}

${ }^{\star}$ ATCC, American Type Culture Collection, Rockville, MD.

$\dagger$ The Forsyth Institute, Boston, MA. 
(Haffajee et al., 1997) of the checkerboard DNA-DNA hybridization method described by Socransky et al. (1994). Samples were lysed by adding $100 \mu \mathrm{l} 0.5 \mathrm{M} \mathrm{NaOH}$ and boiling for $10 \mathrm{~min}$. After neutralizing with $800 \mu \mathrm{l} 5 \mathrm{M}$ ammonium acetate, each sample with denatured DNA was fixed in individual lanes on a nylon membrane (Hybond-N+; Amersham Biosciences), using a Minislot device (Immunetics). Thirty-seven digoxigenin-labelled (Roche Applied Science) whole genomic DNA probes were constructed and hybridized perpendicularly to the lanes of the clinical samples using the Miniblotter 45 (Immunetics). Bound probes were detected using phosphatase-conjugated antibody to digoxigenin (Roche Applied Science) and chemiluminescence (CDP-Star; Amersham Biosciences). Signals were evaluated visually by comparison with the standards at $10^{5}$ and $10^{6}$ bacterial cells for the test species on the same membrane. They were recorded as: 0 , not detected; $1,<10^{5}$ cells; 2 , approximately $10^{5}$ cells; $3,10^{5}-10^{6}$ cells; 4 , approximately $10^{6}$ cells; $5,>10^{6}$ cells. Failure to detect a signal was recorded as zero, although counts in the 1-1000 range could have been present. The sensitivity and specificity of the probes were determined as reported by Socransky et al. (2004). The sensitivity of the assay was adjusted to permit detection of $10^{4}$ cells of a given species by adjusting the concentration of each DNA probe. This procedure was carried out in order to provide the same sensitivity of detection for each probe. In addition, the probes identify $100 \%$ of isolates of species to which the probe is directed. With respect to specificity, over $92 \%$ of all probe: heterologous species reactions did not exhibit cross-reactions. Probes to certain species, such as Por. gingivalis, Treponema denticola and Tannerella forsythia did not cross-react with any heterologous species. The only cross-reactions noted were for species within the same genus, and they varied from genus to genus and species to species within different genera (data not shown).

Data analysis. All statistical tests were performed using the Statistical Package for the Social Sciences (SPSS), release 10.0. Clinical measurements were computed for all sites and the sampled sites in each subject, and then averaged across subjects within the group. Microbial data were expressed as the mean percentage of colonized sites (prevalence) and mean levels $\left(\times 10^{4}\right.$ cells $)$ of each species in the 49 subjects (Haffajee et al., 1997; Colombo et al., 2002). The percentage of samples positive for each species was computed for each subject and averaged across all patients. The levels (scores $0-5$ ) of each species in a sample were converted to absolute numbers, averaged for each subject, and then across the 49 subjects. Significance of differences in clinical parameters, prevalence and levels of subgingival species between periodontitis and periodontally healthy sites was determined using the Wilcoxon signed ranks test. Statistical significance was reached at a $5 \%$ level.

\section{RESULTS}

\section{Clinical data}

A total of 49 adult patients (mean age $46 \cdot 3 \pm 1 \cdot 4$ years; $43 \%$ males; $51 \%$ non-smokers, $27 \%$ past smokers and $22 \%$ smokers) participated in the study. The full mouth periodontal destruction patterns, including mean PPD $(3 \cdot 4 \pm$ $0 \cdot 2 \mathrm{~mm})$, mean CAL $(3 \cdot 6 \pm 0 \cdot 2 \mathrm{~mm})$, mean percentage of sites with BOP $(40 \pm 4 \cdot 1), \mathrm{SB}(44 \pm 4 \cdot 3)$ and SUP $(1 \cdot 3 \pm 0 \cdot 2)$ and mean number of missing teeth $(4 \cdot 7 \pm 2)$, indicated that most of the subjects presented a moderate to severe form of chronic periodontitis (Armitage, 2004). Given the many environmental and host factors that may influence the course of the disease, periodontally healthy sites from the same patients were evaluated as controls. No bleeding or redness was detected in any healthy site, although supragingival plaque accumulation may have been present. Clearly, sites sampled for microbial analysis with periodontitis exhibited signs and symptoms of ongoing periodontal destruction and inflammation (mean PPD $=5 \cdot 8 \pm 0 \cdot 3 \mathrm{~mm}$ and $\mathrm{CAL}=6 \cdot 8 \pm 0 \cdot 3 \mathrm{~mm}$ ) in contrast to periodontally healthy sites (mean PPD $=1 \cdot 8$ $\pm 0 \cdot 1 \mathrm{~mm}$ and $\mathrm{CAL}=2 \cdot 3 \pm 0 \cdot 1 \mathrm{~mm} ; P<0 \cdot 01$, Wilcoxon signed rank test).

\section{Detection of species on or in epithelial cells using DNA probes}

The number of harvested cells obtained directly from a subject's gingival sulcus was determined by counting epithelial cells in 10 random fields of the Nucleopore filter membranes and extrapolating to the area of the entire filter $(12 \mathrm{~mm}$ diameter). Counts indicated that 500-1000 epithelial cells per millilitre were obtained after Percoll gradient centrifugation and filtration (data not shown). These findings are in agreement with data reported by Childs \& Gibbons (1988) and Dibart et al. (1998). Some of the epithelial cell samples collected were lost (82 samples, mostly from healthy sites) during processing, and were excluded from the analysis. Of the 49 patients, 30 subjects had two samples, 16 had three samples, and three patients had four samples from diseased sites (total of 120 samples). Moreover, 36 patients had two samples, one had four samples, two had three samples, and 10 had only one sample collected from healthy sites (92 samples). The mean frequency of detection and levels of specific species present on or in epithelial cell samples from 49 periodontitis subjects are shown in Table 2. Of the species and subspecies tested, only Eikenella corrodens was not detected in any sample at all. The most frequently detected species were Por. gingivalis $(42 \%), T$. denticola (38\%), P. intermedia (37\%), Streptococcus intermedius (36\%), Campylobacter rectus (35\%), Streptococcus sanguinis (35\%) and Streptococcus oralis (34\%). In general, the species were detected in the mean range of $1 \cdot 5 \pm 0 \cdot 4 \times 10^{4}$ cells. Microorganisms found at elevated mean levels included F. nucleatum subsp. vincentii, C. rectus, T. denticola, Campylobacter showae and Veillonella parvula. When the mean frequencies (Fig. 1) and levels (Fig. 2) of the detected species were compared between sites with periodontitis and periodontally healthy sites, no statistically significant differences were found $(P>0 \cdot 05)$. Nonetheless, the data indicated that there were more micro-organisms on or in epithelial cells obtained from periodontal pockets than from healthy sites. Regarding pathogenic species, we observed a mean prevalence of $43 \%$ for Por. gingivalis and $46 \%$ for T. denticola in epithelial samples from periodontal pockets, whereas in samples from healthy sites, the frequencies were 25 and $28 \%$, respectively (Fig. 1). Other potential pathogens that were frequently detected in periodontitis lesions included C. rectus $(45 \%)$ and $P$. intermedia (41\%). Species associated with periodontal health, such as $V$. parvula, S. oralis, Streptococcus gordonii and Streptococcus mitis tended to be more prevalent on epithelial cells from sites without disease (Fig. 1). In contrast, species of Actinomyces were found at 
Table 2. Mean frequency $( \pm S D)$ and counts ( \pm SEM) of the oral bacterial species detected on or in crevicular epithelial cell samples from 49 chronic periodontitis patients

\begin{tabular}{|c|c|c|}
\hline Bacterial species & Mean frequency (\%) & Mean count $\left(\times 10^{4}\right)$ \\
\hline Por. gingivalis & $42 \pm 7 \cdot 4$ & $1 \cdot 4 \pm 0 \cdot 9$ \\
\hline T. denticola & $38 \pm 7 \cdot 4$ & $2 \cdot 7 \pm 0 \cdot 9$ \\
\hline P. intermedia & $37 \pm 7 \cdot 2$ & $1 \cdot 5 \pm 0 \cdot 4$ \\
\hline S. intermedius & $36 \pm 7 \cdot 5$ & $1 \cdot 5 \pm 0 \cdot 4$ \\
\hline C. rectus & $35 \pm 5$ & $3 \cdot 7 \pm 1 \cdot 6$ \\
\hline S. sanguinis & $35 \pm 7 \cdot 3$ & $0 \cdot 7 \pm 0 \cdot 2$ \\
\hline S. oralis & $34 \pm 7 \cdot 2$ & $0 \cdot 4 \pm 0 \cdot 16$ \\
\hline S. gordonii & $30 \pm 7$ & $1 \cdot 4 \pm 0 \cdot 4$ \\
\hline S. anginosus & $30 \pm 7$ & $0 \cdot 6 \pm 0 \cdot 16$ \\
\hline G. morbillorum & $29 \cdot 3 \pm 7$ & $0 \cdot 4 \pm 0 \cdot 2$ \\
\hline S. mitis & $29 \pm 7$ & $0 \cdot 5 \pm 0 \cdot 16$ \\
\hline Sel. noxia & $28 \cdot 6 \pm 7$ & $0 \cdot 4 \pm 0 \cdot 05$ \\
\hline C. showae & $27 \cdot 5 \pm 7$ & $2 \cdot 6 \pm 1 \cdot 3$ \\
\hline F. nucleatum subsp. vincentii & $27 \cdot 4 \pm 7$ & $7 \cdot 4 \pm 2 \cdot 3$ \\
\hline F. nucleatum subsp. polymorphum & $27 \cdot 4 \pm 6 \cdot 6$ & $1 \cdot 0 \pm 0 \cdot 3$ \\
\hline A. actinomycetemcomitans $\mathrm{b}$ & $27 \cdot 4 \pm 6 \cdot 5$ & $0 \cdot 5 \pm 0 \cdot 3$ \\
\hline N. mucosa & $27 \pm 7 \cdot 4$ & $0 \cdot 3 \pm 0 \cdot 06$ \\
\hline Cap. gingivalis & $26 \cdot 3 \pm 6 \cdot 5$ & $1 \cdot 0 \pm 0 \cdot 3$ \\
\hline Tan. forsythia & $26 \cdot 2 \pm 6$ & $0 \cdot 3 \pm 0 \cdot 05$ \\
\hline F. periodonticum & $26 \cdot 2 \pm 7$ & $0 \cdot 2 \pm 0 \cdot 04$ \\
\hline Pro. acnes & $26 \pm 7 \cdot 5$ & $0 \cdot 7 \pm 0 \cdot 3$ \\
\hline Cap. ochracea & $25 \pm 7$ & $0 \cdot 7 \pm 0 \cdot 3$ \\
\hline$V \cdot$ parvula & $23 \pm 6 \cdot 4$ & $2 \pm 0 \cdot 4$ \\
\hline Pep. micros & $21 \cdot 4 \pm 6 \cdot 4$ & $0 \cdot 5 \pm 0 \cdot 2$ \\
\hline Eu. nodatum & $21 \cdot 4 \pm 6 \cdot 4$ & $0 \cdot 2 \pm 0 \cdot 04$ \\
\hline A. actinomycetemcomitans a & $20 \cdot 2 \pm 5$ & $0 \cdot 54 \pm 0 \cdot 3$ \\
\hline L. buccalis & $20 \pm 6 \cdot 4$ & $0 \cdot 8 \pm 0 \cdot 3$ \\
\hline F. nucleatum subsp. nucleatum & $18 \pm 6$ & $1 \cdot 02 \pm 0 \cdot 9$ \\
\hline S. constellatus & $12 \pm 5$ & $0 \cdot 2 \pm 0 \cdot 03$ \\
\hline Am. gerencseriae & $11 \pm 5$ & $0 \cdot 05 \pm 0 \cdot 2$ \\
\hline Am. israelii & $10 \cdot 5 \pm 4 \cdot 5$ & $0 \cdot 06 \pm 0 \cdot 03$ \\
\hline Am. naeslundii 1 & $10 \cdot 5 \pm 4$ & $0 \cdot 03 \pm 0 \cdot 03$ \\
\hline Am. naeslundii II (Am. viscosus) & $10 \pm 5$ & $0 \cdot 03 \pm 0 \cdot 03$ \\
\hline A. odontolyticus & $10 \pm 4 \cdot 3$ & $0 \cdot 04 \pm 0 \cdot 04$ \\
\hline P. nigrescens & $8 \cdot 3 \pm 4$ & $0 \cdot 7 \pm 0 \cdot 3$ \\
\hline Cap. sputigena & $2 \cdot 5 \pm 1 \cdot 6$ & $0 \cdot 017 \pm 0 \cdot 01$ \\
\hline E. corrodens & 0 & 0 \\
\hline
\end{tabular}

low mean prevalence and levels, being detected in $\leqslant 11 \%$ of the epithelial cell samples at a mean count of $\leqslant 0.06 \times 10^{4}$ bacterial cells (Table 2). No significant differences between sites with periodontitis and periodontal health were observed regarding Actinomyces species (Figs 1 and 2).

\section{DISCUSSION}

The great diversity of biological surfaces in the oral cavity provides many ecological sites for colonization with a variety of oral bacterial species (Mager et al., 2003). The interactions between subgingival species and the epithelial cells which line the gingival crevice and periodontal pocket are of great importance in understanding the ecology of the subgingival site in health and disease. Thus, the species present on or in such epithelial cells should be determined. In the present study, we employed an improved methodology reported by Dibart et al. (1998) to separate gingival crevicular epithelial cells with adherent bacteria from nonadherent bacteria. In addition, a greater number of DNA probes and the checkerboard DNA-DNA hybridization technique were utilized for the characterization of the bacterial community associated with the epithelial cells. The checkerboard technique has been widely used to identify microbial complexes within dental biofilms, as well as those associated with different oral epithelia in various clinical conditions (Socransky et al., 1998; Colombo et al., 2002; Mager et al., 2003). This method is rapid, sensitive, and relatively inexpensive. It overcomes many of the limitations of cultural microbiology, including loss of viability of 


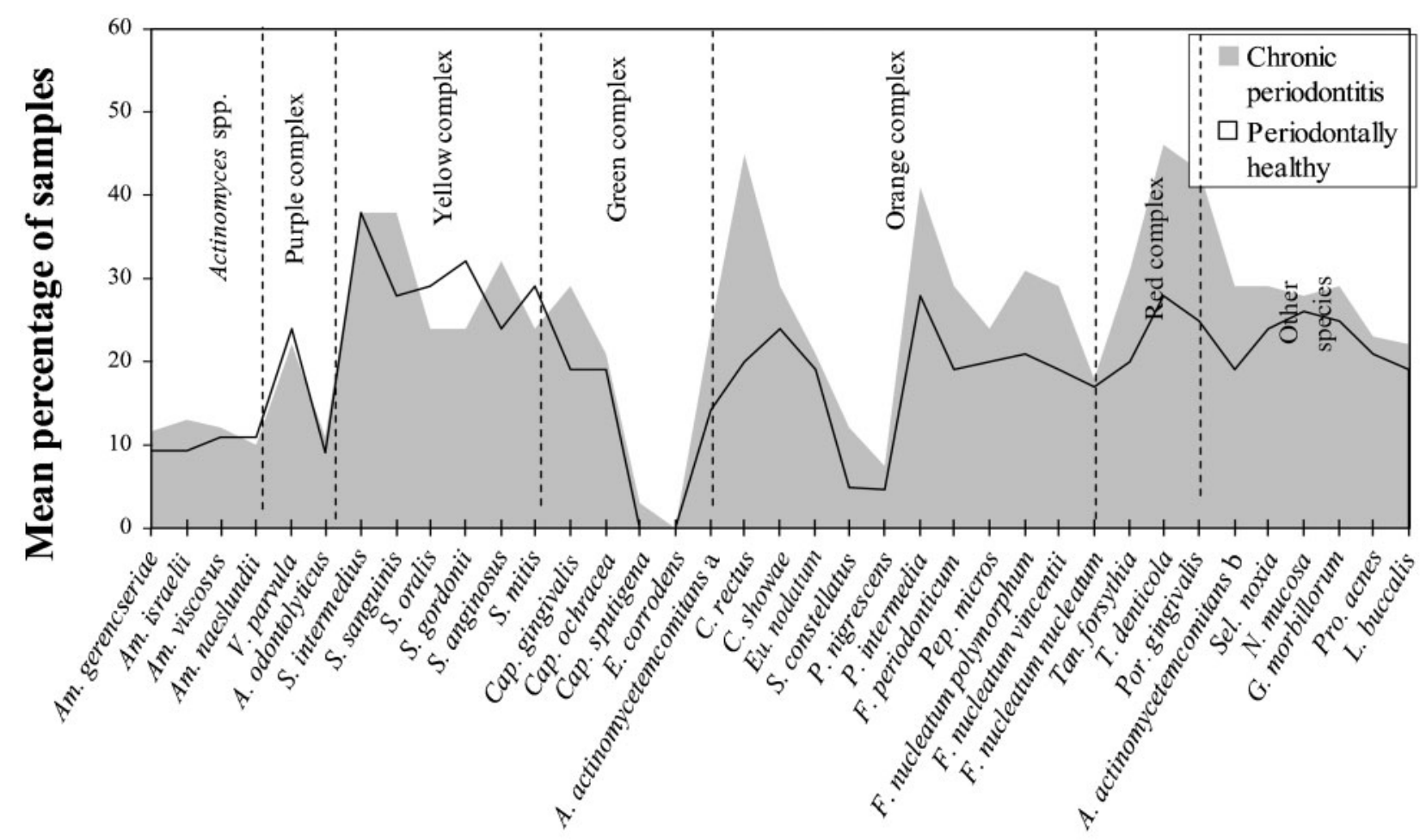

Fig. 1. Profiles of mean percentage of 37 subgingival taxa in epithelial cell samples obtained from 120 sites with periodontitis and 92 periodontally healthy sites from 49 subjects with chronic periodontitis. The frequency of each species was computed for each subject and averaged within the group. No significant differences were observed between diseased and healthy sites ( $P>0.05$; Wilcoxon signed ranks test). The species were ordered according to the microbial complexes described by Socransky et al. (1998).

organisms during transport, and difficulties in enumerating or speciating hard to grow (or even uncultivable) species such as some oral bacteria (Socransky et al., 2004). The microbial data obtained in the current investigation indicated that there were more micro-organisms on or in epithelial cells taken from periodontal pockets than from healthy sites. Similar results were reported by Dibart et al. (1998) and Vaahtoniemi et al. (1993). Specific groups of micro-organisms in the subgingival biofilm described by Socransky et al. (1998) as members of the 'red and orange complexes' have been commonly associated with destructive periodontal disease. Several of these periodontal pathogens, including Por. gingivalis, T. denticola, Tan. forsythia and F. nucleatum, are capable of elaborating a vast array of virulence factors that allow them to adhere to and invade the host cells, avoid or resist the immune response, and cause periodontal tissue damage (Lamont et al., 1995; Madianos et al., 1996; Han et al., 2000; Rudney et al., 2001, 2005; Vitkov et al., 2005). Our data demonstrated that these species showed a trend to be more frequently detected in association with epithelial cells from sites with periodontitis compared to controls. The elevated prevalence of other pathogens, such as $C$. rectus and $P$. intermedia, associated with epithelial cells from periodontitis lesions might also be explained by the presence of surface structures and other molecules that appear to confer mechanisms for evasion of the immune system (Thompson, 2002) and for adherence to and invasion of host cells, including human heart and aortic endothelial cells, smooth muscle and KB cells (a human oral epithelial cell line) (Dorn et al., 1998, 1999). Moreover, adhesion to and invasion of crevicular epithelial cells by oral bacteria may also be influenced by changes that take place in the epithelium during the disease process. Several microbial products and/or host inflammatory mediators may lead to tissue destruction, exposing new receptors on epithelial cells that favour attachment and internalization by a specific group of micro-organisms (Gibbons et al., 1990). An interesting finding from this study was the elevated prevalence of pathogens associated with epithelial cells from periodontally healthy sites. Dibart et al. (1998), for instance, found a quite low prevalence of A. actinomycetemcomitans serotypes a and $b$ in epithelial samples from periodontally healthy subjects. In contrast, we detected these species at a much higher mean frequency in periodontally healthy sites. One possible explanation might be that we examined healthy sites from patients with periodontitis. It has been recognized that healthy sites from individuals with periodontal disease harbour greater numbers of pathogens than sites from subjects with 


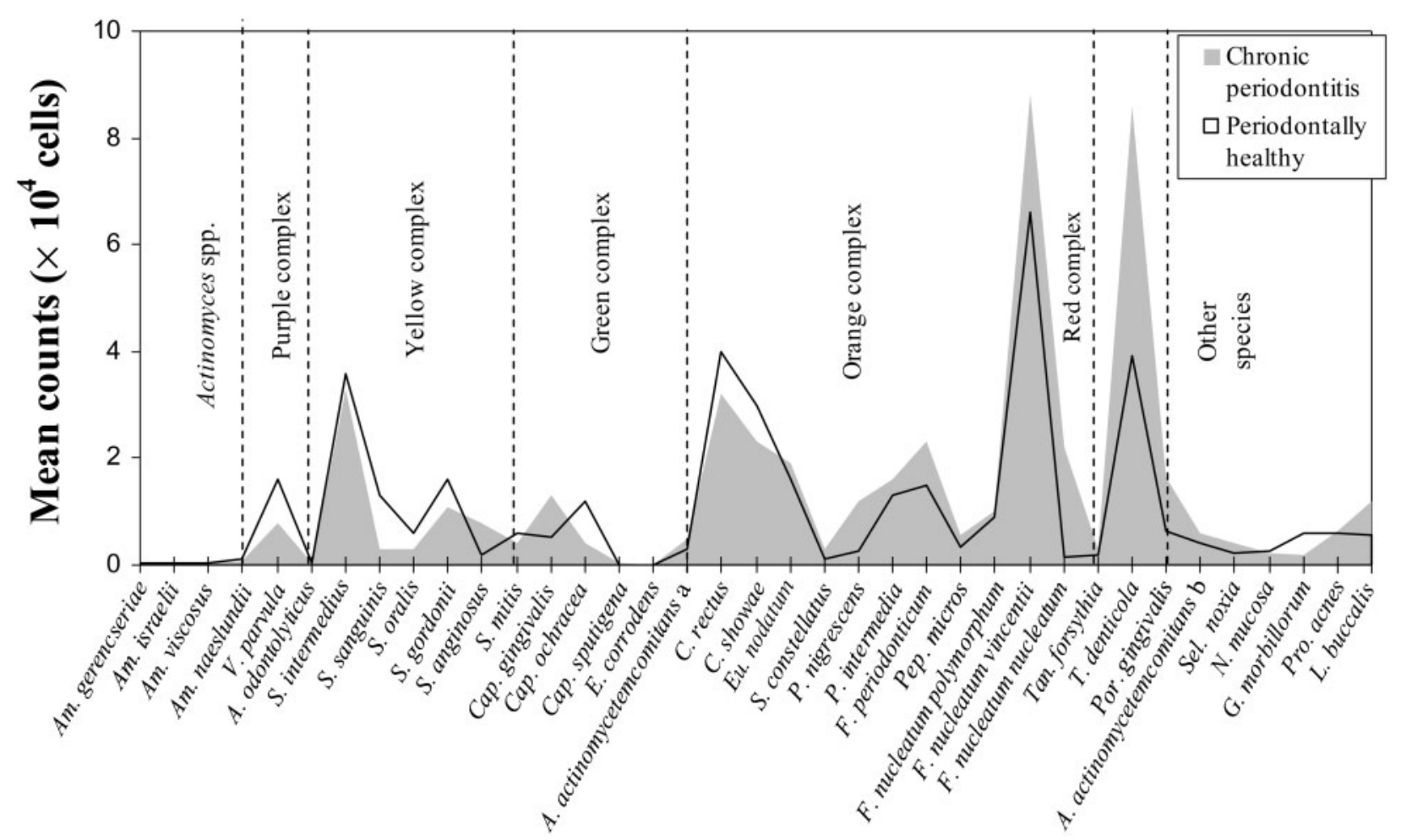

Fig. 2. Profiles of mean levels $\left(\times 10^{4}\right)$ of 37 subgingival taxa in epithelial cell samples obtained from 120 sites with periodontitis and 92 periodontally healthy sites from 49 subjects with chronic periodontitis. The levels of each species were computed for each site and averaged within a subject. No significant differences were observed between diseased and healthy sites $(P>0.05$; Wilcoxon signed ranks test). The species were ordered according to the microbial complexes described by Socransky et al. (1998).

periodontal health (Riviere et al., 1996; Sakamoto et al., 2004). In addition, these species may vary in prevalence and level in populations with different ethnic backgrounds (Haffajee et al., 2004). In a study by Colombo et al. (2002), periodontal pathogens were detected in a very high prevalence, not only in chronic periodontitis patients, but also in subjects with periodontal health from a Brazilian population. Thus, the large bacterial load could lead to a more efficient transmission and colonization by these pathogens from sites and/or subjects with disease to periodontally healthy sites and/or subjects in a population. On the other hand, attachment of periodontal pathogens to oral epithelial cells may be a common event in both health and disease. Studies have indicated that several pathogens can be detected in high numbers on the tongue and buccal mucosa (Asikainen et al., 1991; Mager et al., 2003). Rudney et al. (2001, 2005) demonstrated large masses of bacteria within buccal epithelial cells taken directly from healthy subjects. Species related to periodontal health, such as V. parvula and streptococci, tended to be more prevalent on epithelial cells from sites without disease. These results are consistent with other studies that associate a greater frequency of streptococci with periodontal health (Haffajee et al., 1997; Dibart et al., 1998; Socransky et al., 1998). Actinomyces species are among the most dominant micro-organisms in supra- and subgingival biofilms (Ximenez-Fyvie et al., 2000). However, we found these species at very low frequencies and levels on/in epithelial cells from all tested samples. This may result from the fact that these species seem to colonize hard tissues to a far greater extent than soft tissues (Mager et al., 2003). The data presented in this study suggest that a wide range of bacterial species may be found in or on crevicular epithelial cells obtained from periodontally healthy sulci and periodontal pockets. However, it should be borne in mind that the method employed here could not determine which species were attached to or present within the epithelial cells. Despite this, Rudney et al. (2005) demonstrated that the intracellular microbiota of buccal epithelial cells is polymicrobial. Furthermore, recent studies have revealed that oral bacteria work in consortia, and this may facilitate the colonization of epithelial cells by bacteria unable to adhere or invade directly (Edwards et al., 2005). Crevicular epithelial cells taken from subjects with periodontal health and different forms of disease using in situ hybridization and confocal microscopy are currently being evaluated in our laboratory. Hopefully, such studies will help to clarify several questions regarding the relevance of bacterial invasion in the pathogenesis of periodontal diseases. 


\section{ACKNOWLEDGEMENTS}

This work was supported in part by the Program of Research Support for Groups of Excellence (PRONEX), the National Council for Scientific and Technological Development (CNPq), and the Foundation for Research Financial Support in the State of Rio de Janeiro (FAPERJ), Brazil.

\section{REFERENCES}

Armitage, G. C. (2004). Periodontal diagnoses and classification of periodontal diseases. Periodontol 2000 34, 9-21.

Asikainen, S., Alaluusua, S. \& Saxen, L. (1991). Recovery of $A$ actinomycetemcomitans from teeth, tongue, and saliva. $J$ Clin Periodontol 62, 203-206.

Childs, W. C., III \& Gibbons, R. J. (1988). Use of Percoll density gradients for studying the attachment of bacteria to oral epithelial cells. J Dent Res 67, 826-830.

Colombo, A. P., Teles, R., Torres, M. C., Souto, R. M., Mendes, M. C. S., Rosalem, J. R. W. \& Uzeda, M. (2002). Subgingival microbiota of Brazilian subjects with untreated chronic periodontitis. J Periodontol 73, 360-369.

Dibart, S., Skobe, Z., Snapp, K. R., Socransky, S. S., Smith, C. M. \& Kent, R. (1998). Identification of bacterial species on or in crevicular epithelial cells from healthy and periodontally diseased patients using DNA-DNA hybridization. Oral Microbiol Immunol 13, 30-35.

Dorn, B. R., Leung, K. P. \& Progulske-Fox, A. (1998). Invasion of human oral epithelial cells by Prevotella intermedia. Infect Immun 66, 6054-6057.

Dorn, B. R., Dunn, W. A., Jr \& Progulske-Fox, A. (1999). Invasion of human coronary artery cells by periodontal pathogens. Infect Immun 67, 5792-5798.

Dzink, J. L., Gibbons, R. J., Childs, W. C., III \& Socransky, S. S. (1989). The predominant cultivable microbiota of crevicular epithelial cells. Oral Microbiol Immunol 4, 1-5.

Edwards, A. M., Grossman, T. J. \& Rudney, J. D. (2005). Fusobacterium nucleatum transports noninvasive Streptococcus cristatus into human epithelial cells. Infect Immun 74, 654-662.

Fives-Taylor, P., Meyer, D. \& Mintz, K. (1995). Characteristics of Actinobacillus actinomycetemcomitans invasion of and adhesion to cultured epithelial cells. Adv Dent Res 9, 55-62.

Gibbons, R. J., Hay, D. I., Childs, W. C. \& Davis, G. (1990). Role of cryptic receptors (cryptotypes) in bacterial adhesion to oral surfaces. Arch Oral Biol 35, S1075-S1149.

Haffajee, A. D., Cugini, M. A., Dibart, S., Smith, C., Kent, R. L., Jr \& Socransky, S. S. (1997). The effect of SRP on the clinical and microbiological parameters of periodontal diseases. J Clin Periodontol 24, 324-334.

Haffajee, A. D., Bogren, A., Hasturk, H., Feres, M., Lopez, N. \& Socransky, S. S. (2004). Subgingival microbiota of chronic periodontitis subjects from different geographic locations. J Clin Periodontol 31, 996-1002.

Han, Y. W., Shi, W., Huang, G. T., Kinder Haake, S., Park, N. H., Kuramitsu, H. \& Genco, R. J. (2000). Interactions between periodontal bacteria and human oral epithelial cells: Fusobacterium nucleatum adheres to and invades epithelial cells. Infect Immun 68, 3140-3146.
Lamont, R. J. \& Yilmaz, O. (2002). In or out: the invasiveness of oral bacteria. Periodontol 2000 30, 61-69.

Lamont, R. J., Chan, A., Belton, C. M., Izutzu, K. T., Vasel, D. \& Weinberg, A. (1995). Porphyromonas gingivalis invasion of gingival epithelial cells. Infect Immun 63, 3878-3885.

Madianos, P. N., Papapanou, P. N., Nannmark, U., Dahlen, G. \& Sandros, J. (1996). Porphyromonas gingivalis FDC381 multiplies and persists within human oral epithelial cells in vitro. Infect Immun 64, 660-664.

Mager, D. L., Ximenez-Fyvie, L. A., Haffajee, A. D. \& Socransky, S. S. (2003). Distribution of selected bacterial species on intraoral surfaces. J Clin Periodontol 30, 644-654.

Meyer, D. H., Linppmann, J. E. \& Fives-Taylor, P. (1996). Invasion of epithelial cells by Actinobacillus actinomycetemcomitans: a dynamic, multistep process. Infect Immun 64, 2988-2997.

Peters, S. R., Valdez, M., Rivieri, G. \& Thomas, D. D. (1999). Adherence to and penetration through endothelial cells by oral treponemes. Oral Microbiol Immunol 14, 379-383.

Riviere, G. R., Smith, K. S., Tzagaroulaki, E., Kays, S. L., Zhu, X., DeRouen, T. A. \& Adams, D. F. (1996). Periodontal status and detection frequency of bacteria at sites of periodontal health and gingivitis. J Periodontol 67, 109-115.

Rudney, J. D., Chen, R. \& Sedgewick, G. J. (2001). Intracellular Actinobacillus actinomycetemcomitans and Porphyromonas gingivalis in buccal epithelial cells collected from human subjects. Infect Immun 69, 2700-2707.

Rudney, J. D., Chen, R. \& Sedgewick, G. J. (2005). Actinobacillus actinomycetemcomitans, Porphyromonas gingivalis, and Tannerella forsythensis are components of a polymicrobial intracellular flora within human buccal cells. J Dent Res 84, 59-63.

Sakamoto, M., Huang, Y., Ohnishi, M., Umeda, M., Ishikawa, I. \& Benno, Y. (2004). Changes in oral microbial profiles after periodontal treatment as determined by molecular analysis of $16 \mathrm{~S}$ rRNA genes. JMed Microbiol 53, 563-571.

Sandros, J., Papapanou, P. N., Nannmark, U. \& Dahlen, G. (1994). Porphyromonas gingivalis invades human pocket epithelium in vitro. J Periodontol Res 29, 62-69.

Socransky, S. S., Smith, C., Martin, L., Paster, B. J., Dewhirst, F. E. \& Levin, A. E. (1994). 'Checkerboard' DNA-DNA hybridization. Biotechniques 17, 788-792.

Socransky, S. S., Haffajee, A. D., Cugini, M. A., Smith, C. \& Kent, R. L., Jr (1998). Microbial complexes in subgingival plaque. J Clin Periodontol 25, 134-144.

Socransky, S. S., Haffajee, A. D., Smith, C., Martin, L., Haffajee, J. A., Uzel, N. G. \& Goodson, J. M. (2004). Use of checkerboard DNADNA hybridization to study complex microbial ecosystems. Oral Microbiol Immunol 19, 352-362.

Thompson, S. A. (2002). Campylobacter surface-layers(S-layers) and immune evasion. Ann Periodontol 7, 43-53.

Vaahtoniemi, L. H., Raisanen, S. \& Sterfors, L.-E. (1993). Attachment of bacteria to oral epithelial cells in vivo: a possible correlation to gingival health status. J Periodont Res 28, 308-311.

Vitkov, L., Krautgartner, W. D. \& Hanning, M. (2005). Bacterial internalization in periodontitis. Oral Microbiol Immunol 20, 317-321.

Ximenez-Fyvie, L. A., Haffajee, A. D. \& Socransky, S. S. (2000). Microbial composition of supra- and subgingival plaque in subjects with adult periodontitis. J Clin Periodontol 27, 722-732. 